\title{
Cost-Effectiveness Analysis of Treatment Options for Acute Otitis Media
}

\author{
Andrew S. Coco, MD, MS \\ Von Hess Healthcare Research Center, \\ Family and Community Medicine, Lan- \\ caster General Hospital, Lancaster, Pa
}

Conflicts of interest: none reported

\section{CORRESPONDING AUTHOR}

Andrew S. Coco, MD, MS

Von Hess Healthcare Research Center Family and Community Medicine

Lancaster General Hospital

$555 \mathrm{~N}$ Duke St

Lancaster, PA 17604-3555

ascoco@lancastergeneral.org

\begin{abstract}
PURPOSE This study evaluated the costs and utility of observation and routine antibiotic treatment options for children with acute otitis media.

METHODS The cost-effectiveness analysis was performed among children aged 6 months to 12 years seen in primary care offices. The interventions studied were watchful waiting as practiced in the Netherlands, delayed prescription, 5 days of amoxicillin, and 7 to 10 days of amoxicillin. The main outcome measure was cost per quality-adjusted life-year (QALY).
\end{abstract}

RESULTS In the base case analysis, delayed prescription was the least costly option and 7 to 10 days of amoxicillin was the most effective. The incremental cost utility ratio (ICUR) of 7 to 10 days of amoxicillin compared with delayed prescription was $\$ 56,000$ per QALY gained. Watchful waiting and 5 days of amoxicillin were inferior options. The results were sensitive to the rate of nonattendance in the delayed prescription strategy: when the rate was less than $23 \%$, watchful waiting was the least costly option and delayed prescription was an inferior option. Probabilistic sensitivity analysis, in which all model variables were simultaneously varied, showed with 95\% certainty that compared with delayed prescription, 7 to 10 days of amoxicillin had a $61 \%$ probability of having an ICUR of greater than $\$ 50,000$ per QALY gained, and watchful waiting had a $23 \%$ probability of having an ICUR of less than $\$ 50,000$ per QALY gained.

CONCLUSIONS Economically, an approach to the treatment of acute otitis media with either an initial period of observation or routine treatment with amoxicillin is reasonable.

Ann Fam Med 2007;5:29-38. DOI: 10.1370/afm.626

\section{INTRODUCTION}

cute otitis media $(\mathrm{AOM})$, or inflammation of the middle ear, is
responsible for 13.6 million pediatric office visits annually in the
United States ${ }^{1}$ at an estimated annual cost of $\$ 2.98$ billion in $1995 .^{2}$ In the United States, AOM is routinely treated with antibiotics and, because of the large number of visits, accounts for a considerable percentage of all outpatient antimicrobial prescriptions. ${ }^{3,4}$ The benefit of antibiotic treatment of AOM is controversial, however, for children older than 6 months. ${ }^{5-8}$ Meta-analyses and systematic reviews of the literature have found a spontaneous resolution rate of $81 \%$ compared with a $93 \%$ resolution rate with antibiotic therapy, for an overall benefit of shortening the course of AOM by 1 day in 1 of 8 children treated. ${ }^{9-12}$ Suppurative complications, such as acute mastoiditis, are rare, ${ }_{1}^{13}$ and the extensive use of antibiotics contributes to bacterial resistance. ${ }^{14-20}$

Several recent reports document the efficacy and safety of 2 alternative, observational approaches to routine use of antibiotics: delayed prescription and watchful waiting. ${ }^{21-24}$ These approaches involve waiting for 72 hours to see if symptoms improve before instituting antibiotic therapy. Routine antibiotic treatment is the usual option for treating AOM in the United States, but recent guidelines have allowed for observation of chil- 
dren in whom the infection is less severe. ${ }^{25}$ The extent to which clinicians will adopt this approach remains to be seen. Because of the controversy, an economic analysis would be useful in clarifying these issues. The purpose of this study was to examine the economic implications of observational and routine antibiotic treatment approaches to AOM through a cost-effectiveness analysis.

\section{METHODS}

\section{Decision Model}

The study was an incremental cost utility analysis of 4 strategies for treating AOM using a decision analytic model. The analysis adopted a societal perspective that includes non-health care costs of parental work loss and transportation. The analysis was performed in patients aged 6 months to 12 years seen in primary care offices with uncomplicated, sporadic AOM who had not received antibiotics in the previous month or who had documentation that a previous episode of AOM treated with antibiotics within the last month had resolved. The model compared the cost and utility of 4 management strategies: (1) watchful waiting (72 hours of observation to see if symptoms improve before starting amoxicillin) as currently practiced in the Netherlands, ${ }^{26}(2)$ delayed prescription, in which patients return to the office for a prescription of amoxicillin if symptoms persist for 48 to 72 hours, ${ }^{21}$ (3) routine treatment with 5 days of amoxicillin, and (4) routine treatment with 7 to 10 days of amoxicillin. (These treatment lengths represent the usual duration of therapy in Europe and the United States; efficacy but not cost is similar. The cost of 8.5 days of amoxicillin, an average of the latter 2 lengths, was used in the model..$^{10}$ )

The time frame for the study was 30 days. The scope of the model was limited to short-term outcomes of AOM because of a lack of differences between antibiotic and placebo groups in the longer-term outcomes of recurrent $\mathrm{AOM}$, tympanic membrane rupture, and middle ear effusion, as shown in prior studies. ${ }^{2,9-11}$ The included short-term outcomes were resolution (absence of AOM symptoms such as fever and ear pain) and clinical failure (continuation of AOM symptoms for 3 days while being observed or while receiving amoxicillin).

The study used costs rather than charges and included societal costs of parental work time lost and non-health care expenses, such as those for transportation and over-the-counter medical supplies. Benefits of the interventions, aside from resolution of AOM symptoms, included a reduced rate of mastoiditis with routine use of antibiotics and a decreased likelihood of reconsultation for future episodes of $\mathrm{AOM}$ under the observational strategies. Harms from the interventions included gastrointestinal and dermatologic adverse effects of antibiotics. Excluded from the model were the benefits of decreased antibiotic resistance with observational strategies, decreased reconsultation rates with other self-limiting upper respiratory tract infections, and parental satisfaction gained from knowledge of contributing to reduced antibiotic resistance through observational strategies. None of the children in the model developed meningitis. ${ }^{13}$

\section{Model Pathways and Estimates of Clinical Factors}

The model was programmed using statistical software (TreeAge Pro 2005, healthcare version; TreeAge Software Inc, Williamstown, Mass). The decision tree is shown in Figure 1. Values and assumptions used for the various management strategies and possible outcomes were as follows.

- Watchful waiting: In the Netherlands, $20.3 \%$ of parents do not seek consultation for AOM. ${ }^{27}$ It was assumed that children of these parents had mild disease, experiencing a clinical failure rate of $7.7 \% .{ }^{28}$ The other $79.7 \%$ of children had an office visit and were observed with a follow-up plan to contact the physician if symptoms worsened or did not improve in 72 hours. ${ }^{26,27}$ Observed children experienced a clinical failure rate of $17.5 \%{ }^{27}$ within 3 days that necessitated a second office visit and treatment with 7 to 10 days of amoxicillin, leading to resolution.

- Delayed prescription: As for watchful waiting, a proportion of children with AOM were not brought in for a visit. The nonattendance rate was $37 \%$ for the delayed prescription strategy. ${ }^{21}$ Again, children not seen were assumed to have mild disease, and the majority experienced spontaneous resolution. The clinical failure rate was $7.7 \%$, and these children required a consultation and 7 to 10 days of amoxicillin, leading to resolution. ${ }^{28}$ The remaining $63 \%$ of children were seen for a consultation, and their parents were informed that a prescription for 7 to 10 days of amoxicillin was available at the office for collection should symptoms persist for 3 days. Clinical failure occurred in 24\%, and the prescription was used with subsequent resolution. ${ }^{21}$ In the remaining children under observation, symptoms resolved spontaneously.

- Routine antibiotic strategies: In North America, where antibiotics are routinely prescribed, the nonattendance rate for $\mathrm{AOM}$ is $6 \% .{ }^{27}$ In this analysis, the children not seen were assumed to have mild disease and also had a clinical failure rate of $7.7 \% .{ }^{28}$ Those who experienced a failure were brought in for a consultation, treated with 7 to 10 days of amoxicillin, and experienced resolution. The remaining $94 \%$ of children were seen and treated with either 5 days or 7 to 10 days of amoxicillin. The option of 7 to 10 days was assumed to 
Figure 1. Decision tree for treatment strategies for acute otitis media.

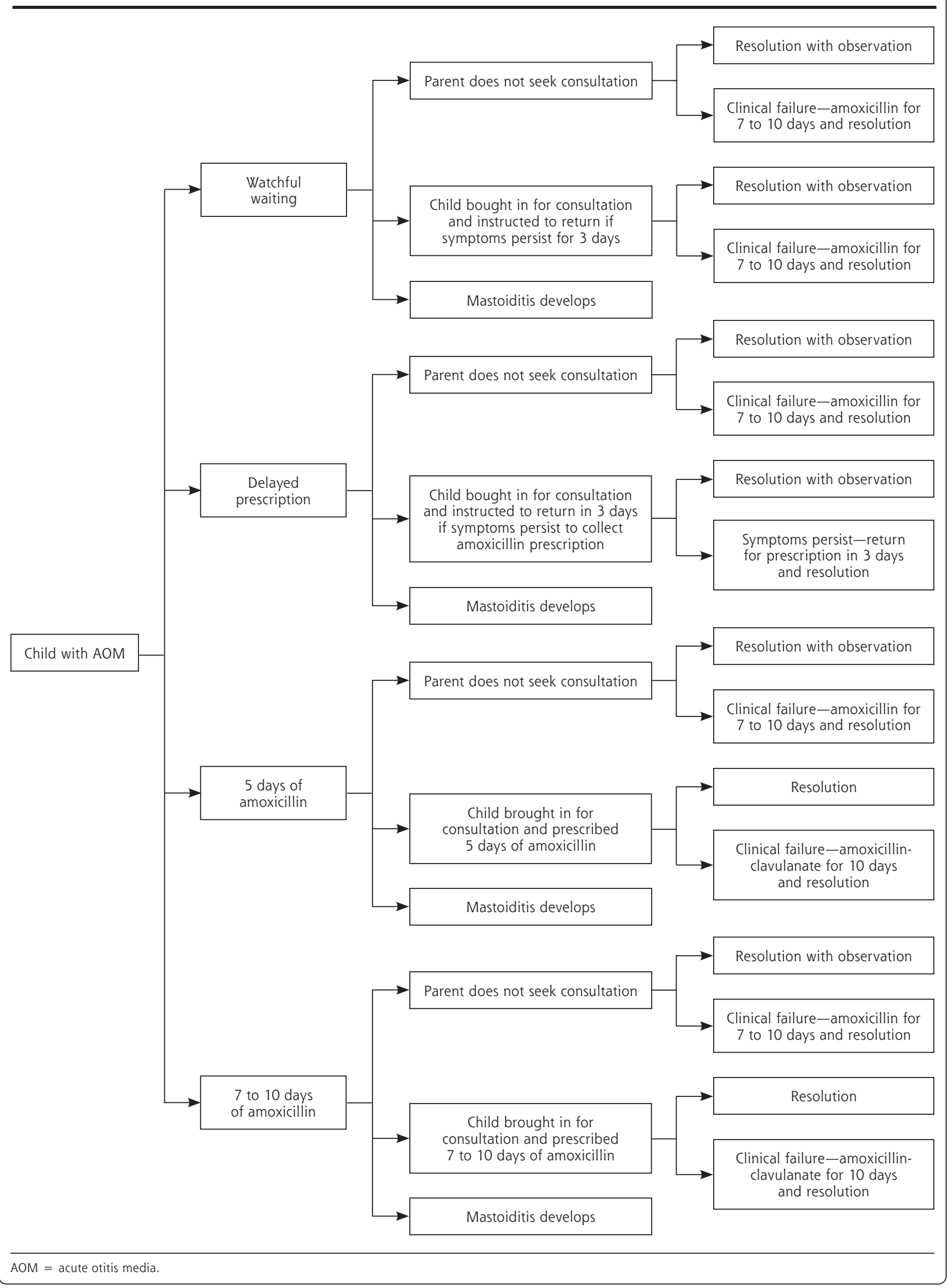


have the same efficacy as 10 days of amoxicillin based on a meta-analysis that used random-effects estimates of pooled absolute rate differences of outcomes for antibiotic effectiveness in which both lengths of treatment were combined.$^{10}$ Children who received 7 to 10 days of treatment experienced resolution of symptoms or clinical failure at a rate of $6.1 \%{ }^{28}$ requiring a second office consultation, treatment with 10 days of amoxicillin-clavulanate, and subsequent resolution. The resolution rate with the 5-day regimen was slightly lower based on a meta-analysis that showed an odds ratio of 1.52 for clinical failure at 8 to 19 days when compared with a regimen of 7 to 10 days. ${ }^{29}$ Children in all pathways treated with antibiotics had a $9.9 \%$ probability of experiencing gastrointestinal adverse effects (based on the difference between antibiotic and control groups in the 3 recent trials that reported on this outcome ${ }^{21,30,31}$ ) and a $2 \%$ risk of dermatologic adverse effects. ${ }^{32}$

- Mastoiditis: Children in all treatment groups could develop acute mastoiditis, although a study has shown that rates are almost double in the Netherlands compared with Great Britain and the United States. ${ }^{33}$ One half of the national rates from that study (Table 1) were used in the model, as only $50 \%$ of children with mastoiditis have preceding AOM. ${ }^{41-44}$ The Netherlands' rate was applied in the watchful waiting and delayed prescription interventions, and the US rate in the amoxicillin interventions.

\section{Model Estimates: Costs}

Various costs in the analysis were estimated as follows.

- Antibiotic cost: These costs were calculated using published average wholesale drug costs and handling costs. ${ }^{35}$ Amoxicillin doses were calculated for a child weighing $12.25 \mathrm{~kg}$ (the mean weight of a 24-month-old) at $45 \mathrm{mg} / \mathrm{kg}$ per day for 8.5 days in the 7-to 10 -day treatment arm and for 5 days in the 5-day treatment arm. ${ }^{34}$ The cost of amoxicillin-clavulanate was based on the same child weight at a dose of $90 \mathrm{mg} / \mathrm{kg}$ per day using the ES suspension containing $600 \mathrm{mg}$ of amoxicillin/5 $\mathrm{mL}$ for 10 days. The cost of ceftriaxone (used only in the acute mastoiditis pathway) included the cost of 2 additional nurse visits to administer the injection. The cost of a nurse visit was estimated at $\$ 13.80$ based on the national average Medicare reimbursement ${ }^{45}$ using code 99211.40 of the International Classification of Diseases, Ninth Revision, Clinical Modification (ICD-9-CM).

- Mastoiditis cost: The cost of hospitalization for acute mastoiditis was calculated from the Healthcare Cost and Utilization Project (HCUP) 2000 database. $^{46}$ A cost-to-charge ratio of 0.55 was used to convert charges to costs based on recommendations of the Association of Healthcare Research and Quality. The average length of stay was 3.7 days. It was assumed that mastoiditis required 7 days of intravenous antibiotics and then 7 days of an oral second-line antibi-

\section{Table 1. Baseline Estimates for a Cost-Effectiveness Analysis of 4 Treatment Strategies for Acute Otitis Media}

\begin{tabular}{|c|c|c|c|c|}
\hline Variable & Baseline & $\begin{array}{l}\text { Low } \\
\text { Sensitivity }\end{array}$ & $\begin{array}{l}\text { High } \\
\text { Sensitivity }\end{array}$ & Reference(s) \\
\hline \multicolumn{5}{|l|}{ Clinical factors } \\
\hline Probability of mastoiditis-W/W/DP & 0.000019 & 0.000 & 0.000038 & 1,34 \\
\hline $\begin{array}{l}\text { Probability of mastoiditis- } \\
\text { routine amoxicillin }\end{array}$ & 0.000010 & 0.000 & 0.000020 & 1,34 \\
\hline Probability of nonattendance-WW & 0.203 & 0.173 & 0.233 & 35 \\
\hline Probability of nonattendance-DP & 0.37 & 0.292 & 0.448 & 23 \\
\hline $\begin{array}{l}\text { Probability of nonattendance- } \\
\text { routine amoxicillin }\end{array}$ & 0.06 & 0.044 & 0.076 & 27 \\
\hline $\begin{array}{l}\text { Probability of clinical failure with } \\
\text { nonattendance-any strategy }\end{array}$ & 0.077 & 0.053 & 0.101 & 28 \\
\hline $\begin{array}{l}\text { Probability of clinical failure; prescrip } \\
\text { tion for amoxicillin redeemed-DP }\end{array}$ & 0.24 & 0.172 & 0.308 & 21 \\
\hline Probability of clinical failure-WW & 0.175 & 0.147 & 0.203 & 27 \\
\hline $\begin{array}{l}\text { Probability of clinical failure- } \\
\text { routine amoxicillin }\end{array}$ & 0.061 & 0.044 & 0.078 & 28 \\
\hline Probability of GI adverse effects & 0.099 & 0.042 & 0.156 & $21,30,31$ \\
\hline $\begin{array}{l}\text { Probability of dermatologic } \\
\text { adverse effects }\end{array}$ & 0.02 & 0.000 & 0.04 & 32 \\
\hline \multicolumn{5}{|l|}{ Costs, \$ } \\
\hline Amoxicillin & 9.40 & 7.74 & 14.95 & 36 \\
\hline Amoxicillin-clavulanate & 47.80 & 31.22 & 71.70 & 36 \\
\hline Hospitalization for mastoiditis & $5,340.00$ & $2,670.00$ & $10,680.00$ & 33 \\
\hline $\begin{array}{l}\text { Home IV antibiotics for mastoiditis } \\
\text { (includes home nurse visits) }\end{array}$ & 305.00 & 178.00 & 545.00 & 36,37 \\
\hline Office consultation & 34.23 & 17.12 & 68.46 & 37,38 \\
\hline Non-health care & 15.08 & 7.54 & 30.16 & 39 \\
\hline Work loss & 91.00 & 46.00 & 182.00 & 39 \\
\hline \multicolumn{5}{|l|}{ Utilities } \\
\hline Day of AOM & 0.79 & 0.713 & 0.867 & 40 \\
\hline Day of treatment success & 0.96 & 0.942 & 0.978 & 40 \\
\hline Day of treatment failure & 0.72 & 0.646 & 0.794 & 40 \\
\hline Gl adverse effects from antibiotics & 0.70 & 0.608 & 0.792 & 40 \\
\hline Rash from antibiotics & 0.77 & 0.694 & 0.846 & 40 \\
\hline
\end{tabular}


otic. ${ }^{47}$ Outpatient costs were estimated as 3.3 days of home intravenous ceftriaxone ${ }^{35}$ to complete the total of 7 days (home nurse visit costs were estimated using the Medicaid rate for Lancaster, $\mathrm{Pa}$ ), then 7 days of a second-line antibiotic. The baseline costs for parental work loss and for non-health care expenses, as discussed subsequently, were tripled. It was assumed that children had 2 outpatient consultations after discharge.

- Nonmedical cost: Work loss and non-health care costs were obtained from a report based on a random sample of 300 interviews with parents of children receiving a diagnosis of AOM in the Kaiser Permanente system in California from 1997. ${ }^{48}$ In this report, the average family lost 5.6 hours of work and spent $\$ 13$ on nonmedical costs including babysitting, day care, travel, parking, and other expenses from an episode of simple AOM. The cost of work loss was estimated based on the US mean hourly wage from a national compensation survey for 2001 (\$16.23), ${ }^{49}$ multiplied by the 5.6 hours. It was assumed that $80 \%$ of the non-health care costs were for transportation and that a physician consultation and trip to the pharmacy, if needed, required 2 hours of work time. A trip to the office and pharmacy to collect and fill a prescription required 1 hour of work time. In the clinical failure pathways, work loss and non-health care costs were doubled, commensurate with a doubling of utility loss.

- Outpatient consultation cost: The cost of an initial outpatient consultation was estimated to be $\$ 34.23$, a value obtained from the average rate of reimbursement for 67,367 Medicaid claims for the diagnosis of AOM in the state of Pennsylvania for 2001. ${ }^{36}$ Follow-up consulta- tions were assumed to be (ICD-9-CM) code 99212 and to cost 0.76 of the initial consultation based on data from the US Centers for Medicare \& Medicaid Services. ${ }^{45}$

All costs were adjusted to US dollars for the year 2001 based on the US medical consumer price index. ${ }^{50}$ Costs and utilities were not discounted because the time frame of the study was only 30 days.

\section{Model Estimates: Effectiveness}

Utility estimates were obtained from a cost utility analysis of second-line antibiotics used in AOM treatment. ${ }^{40}$ In that analysis, a postal survey describing a standardized scenario of a 2-year-old child with AOM was administered to a panel of pediatricians. Responses were used to generate utility scores defined as a preference for each health state rated on a scale of severity from 0 (death) to 1 (perfect health). Health states were rated on a $10-\mathrm{cm}$ visual analogue scale. The following health states were included: AOM, treatment success, treatment failure, and gastrointestinal or dermatologic adverse events secondary to antibiotic therapy. Utility values for these outcomes are given in Table 1.

In the present analysis, children experienced 1 of 5 possible outcomes: (1) resolution with observation, (2) clinical failure with observation, but subsequent resolution with 7 to 10 days of amoxicillin, (3) resolution with 5 days or 7 to 10 days of amoxicillin, (4) clinical failure with amoxicillin, but subsequent resolution with 10 days of amoxicillin-clavulanate, or (5) development of acute mastoiditis. Calculations for the utility tolls, in quality-adjusted life-days, for the first 4 pathways are given in Table 2. It was assumed that an episode of acute

\begin{tabular}{|c|c|c|c|c|c|c|}
\hline Pathway & $\begin{array}{c}\text { A } \\
\text { Days of AOM* }\end{array}$ & $\begin{array}{c}\text { B } \\
\text { Days of } \\
\text { Treatment } \\
\text { Success* }\end{array}$ & $\begin{array}{c}\text { C } \\
\text { Days of } \\
\text { Treatment } \\
\text { Failure* }\end{array}$ & $\begin{array}{c}\text { D } \\
\text { Days of } \\
\text { Gl Adverse } \\
\text { Effects*† }\end{array}$ & $\begin{array}{l}\text { E } \\
\text { Days of } \\
\text { Rash* }\end{array}$ & $\begin{array}{l}\text { Total } \\
\text { QALDs Lost§ } \\
(95 \% \mathrm{Cl})\end{array}$ \\
\hline $\begin{array}{l}\text { Resolution with } \\
\text { observation }\end{array}$ & $\begin{array}{c}2.7 \times 0.79= \\
2.1330\end{array}$ & $\begin{array}{c}27.3 \times 0.96= \\
26.2080\end{array}$ & 0 & 0 & 0 & $\begin{array}{c}1.6590 \\
(0.7686-2.3583)\end{array}$ \\
\hline Clinical failure & $\begin{array}{c}2.7 \times 0.79= \\
2.1330\end{array}$ & $\begin{array}{c}20.062 \times 0.96= \\
19.2595\end{array}=$ & $\begin{array}{c}7 \times 0.72= \\
5.0400\end{array}$ & $\begin{array}{c}0.198 \times 0.7= \\
0.1386\end{array}$ & $\begin{array}{c}0.04 \times 0.77= \\
0.0308\end{array}$ & $\begin{array}{c}3.3981 \\
(2.2898-4.5063)\end{array}$ \\
\hline $\begin{array}{l}\text { Resolution with } \\
\text { amoxicillin }\end{array}$ & $\begin{array}{c}2.7 \times 0.79= \\
2.1330\end{array}$ & $\begin{array}{c}27.062 \times 0.96= \\
25.9795\end{array}=$ & 0 & $\begin{array}{c}0.198 \times 0.7= \\
0.1386\end{array}$ & $\begin{array}{c}0.04 \times 0.77= \\
0.0308\end{array}$ & $\begin{array}{c}1.7181 \\
(1.0018-2.4344)\end{array}$ \\
\hline $\begin{array}{l}\text { Clinical failure } \\
\text { with amoxicillin }\end{array}$ & $\begin{array}{c}2.7 \times 0.79= \\
2.1330\end{array}$ & $\begin{array}{c}19.824 \times 0.96= \\
19.0310\end{array}$ & $\begin{array}{c}7 \times 0.72= \\
5.0400\end{array}$ & $\begin{array}{c}0.396 \times 0.7= \\
0.2772\end{array}$ & $\begin{array}{c}0.08 \times 0.77= \\
0.0616\end{array}=$ & $\begin{array}{c}3.4572 \\
(2.3319-4.5824)\end{array}$ \\
\hline \multicolumn{7}{|c|}{$\mathrm{AOM}$ = acute otitis media; GI = gastrointestinal; QALDs = quality-adjusted life-days; $\mathrm{Cl}$ = confidence interval. } \\
\hline \multicolumn{7}{|c|}{$\begin{array}{l}\text { Notes: Clinical failure }=\text { continuation of symptoms after } 2.7 \text { days of observation and subsequent resolution with } 7 \text { to } 10 \text { days of amoxicillin. Clinical failure with amoxi } \\
\text { cillin }=\text { continuation of symptoms after } 2.7 \text { days of amoxicillin and subsequent resolution with } 10 \text { days of amoxicillin-clavulanate. }\end{array}$} \\
\hline \multirow{2}{*}{\multicolumn{7}{|c|}{$\begin{array}{l}\text { * Baseline utilities were used: } 0.79 \text { utility per day for days of AOM; } 0.96 \text { for days of treatment success, } 0.72 \text { for days of treatment failure, } 0.70 \text { for days of } \mathrm{Gl} \text { adverse } \\
\text { effects, and } 0.77 \text { for days of rash. } \\
+ \text { Children receiving amoxicillin had a } 9.9 \% \text { chance of having } 2 \text { days of } \mathrm{Gl} \text { adverse effects. Children receiving amoxicillin and then amoxicillin-clavulanate had a } \\
9.9 \% \text { chance of having } 4 \text { days of } \mathrm{Gl} \text { adverse effects. }\end{array}$}} \\
\hline & & & & & & \\
\hline \multicolumn{7}{|c|}{$\begin{array}{l}\text { \# Children receiving amoxicillin had a } 2 \% \text { chance of having } 2 \text { days of rash. Children receiving amoxicillin and then amoxicillin-clavulanate had a } 2 \% \text { chance of having } \\
4 \text { days of rash. }\end{array}$} \\
\hline \multicolumn{7}{|c|}{$\S$ QALDs lost were calculated by subtracting the sum of columns A through $E$ from the study time frame of 30 days. } \\
\hline
\end{tabular}


mastoiditis had twice the impact on quality of life as did clinical failure with routine treatment with amoxicillin.

\section{Sensitivity Analyses}

The sensitivity analyses evaluated how the model's results changed as the key assumptions were varied over the ranges delimited by the Low Sensitivity and High Sensitivity values in Table 1 . Ninety-five percent confidence intervals were used when reported or calculable from reported data. Costs were varied from $50 \%$ to $200 \%$ of the baseline value. One-way sensitivity analyses were performed for all the variables in the model. Additionally, probabilistic sensitivity analysis, in which the values for all the variables were simultaneously varied, was performed. ${ }^{37}$ Each variable was entered as a probability distribution based on the range indicated in Table 1. The normal distribution was used for cost variables, and the beta distribution was used for the probability and utility variables. ${ }^{37}$ New values from within each of the probability distributions were randomly selected during each of 100,000 iterations, and 95\% likelihood comparisons of the strategies were calculated.

\section{RESULTS}

\section{Baseline Analysis}

The results of the baseline analysis are shown in Table 3. Seven to 10 days of amoxicillin resulted in the highest utility score and had an incremental cost utility ratio (ICUR) of nearly $\$ 55,900$ per quality-adjusted life-year (QALY) gained compared with the least costly option, delayed prescription. Watchful waiting and the 5-day amoxicillin option were inferior. The routine amoxicillin strategies incurred higher overall costs, primarily because of higher costs for antibiotics and office consultations, compared with the 2 observational strategies. The delayed prescription strategy incurred the lowest costs by avoiding a second office consultation for clinical failure. The percentage of children treated with antibiotics was $15.5 \%$ with the watchful waiting approach, $17.9 \%$ with the delayed prescription approach, and $94.5 \%$ with the 2 routine antibiotic approaches.

\section{One-Way Sensitivity Analyses}

One-way sensitivity analysis was performed for all variables using the ranges indicated in Table 1. Because the ICUR of 7 to 10 days of amoxicillin compared with delayed prescription was close to the customary, acceptable, US standard of $\$ 50,000$ per QALY gained, altering the values of several of the cost, clinical, and utility variables affected the base case results. The variables with the greatest impact on the base case results are listed in Table 4. Changing the rates of nonattendance and prescription redemption in delayed prescription had the greatest impact on the ICUR of 7 to 10 days of amoxicillin compared with delayed prescription. The viability of the watchful waiting option was also affected by the nonattendance rate in delayed prescription. Specifically, delayed prescription was dominated by watchful waiting when the nonattendance rate in delayed prescription was less than $23 \%$ and had a lower ICUR than 7 to 10 days of amoxicillin compared with delayed prescription when the delayed prescription nonattendance rate was between $23 \%$ and $28 \%$ (data not shown). When the delayed prescription nonattendance rate was greater than $28 \%$, watchful waiting was dominated by a blend of the delayed prescription and 7 to 10 days of amoxicillin strategies.

\section{Probabilistic Sensitivity Analysis}

The results of the probabilistic sensitivity analysis demonstrated that 7 to 10 days of amoxicillin had a

\begin{tabular}{|c|c|c|c|c|}
\hline Variable & $\begin{array}{l}\text { Delayed } \\
\text { Prescription }\end{array}$ & $\begin{array}{l}\text { Watchful } \\
\text { Waiting }\end{array}$ & $\begin{array}{l}7 \text { to } 10 \text { Days } \\
\text { of Amoxicillin }\end{array}$ & $\begin{array}{l}5 \text { Days of } \\
\text { Amoxicillin }\end{array}$ \\
\hline \multicolumn{5}{|l|}{ Cost, $\$$} \\
\hline Non-health care & 12.78 & 14.52 & 15.10 & 15.47 \\
\hline Work loss & 95.31 & 98.43 & 94.70 & 97.34 \\
\hline Office consultation & 22.52 & 31.47 & 33.83 & 34.61 \\
\hline Antibiotic & 1.68 & 1.47 & 11.61 & 9.42 \\
\hline Mastoiditis & 0.11 & 0.11 & 0.06 & 0.06 \\
\hline Total & 132.40 & 146.00 & 155.30 & 156.90 \\
\hline Incremental cost , \$ & - & 13.60 & 9.30 & 1.60 \\
\hline Effectiveness, QALYs & 0.99460 & 0.99472 & 0.99501 & 0.99487 \\
\hline $\begin{array}{l}\text { Incremental effective- } \\
\text { ness, QALYs }\end{array}$ & - & 0.00012 & 0.00029 & -0.00014 \\
\hline $\begin{array}{l}\text { Cost-effectiveness, } \\
\$ \text { per QALY }\end{array}$ & 133.12 & 146.77 & 156.08 & 157.71 \\
\hline $\begin{array}{l}\text { Incremental cost utility } \\
\text { ratio, \$ per QALY }\end{array}$ & - & $\begin{array}{c}\text { Extended } \\
\text { dominance* }\end{array}$ & 55,853 & Dominated ${ }^{t}$ \\
\hline \multicolumn{5}{|c|}{ QALYs = quality-adjusted life-years. } \\
\hline \multicolumn{5}{|c|}{$\begin{array}{l}\text { Notes: Each column was compared with the one to its left. The incremental cost utility ratio of } 7 \text { to } 10 \text { days of } \\
\text { amoxicillin was compared with delayed prescription. }\end{array}$} \\
\hline \multicolumn{5}{|c|}{$\begin{array}{l}\text { * Watchful waiting was dominated by blend of delayed prescription and } 7 \text { to } 10 \text { days of amoxicillin. } \\
\dagger \text { This option cost more and had less utility. }\end{array}$} \\
\hline
\end{tabular}




\begin{tabular}{|c|c|c|}
\hline Variable & $\begin{array}{l}\text { Variable } \\
\text { Range }\end{array}$ & Effect on ICUR \\
\hline Amoxicillin cost, \$ & 7.74-14.95 & $54,200-68,000$ \\
\hline Non-health care cost, $\$$ & $7.54-30.16$ & $54,500-62,200$ \\
\hline Office consultation cost, $\$$ & $17.12-68.46$ & $43,300-85,600$ \\
\hline Work loss cost, $\$$ & $46-182$ & $58,100-56,000$ \\
\hline Probability of clinical failure-routine amoxicillin & $0.044-0.078$ & $42,000-80,300$ \\
\hline Probability of $\mathrm{Gl}$ adverse effects from antibiotic & $0.042-0.156$ & $49,200-68,900$ \\
\hline Probability of nonattendance-routine amoxicillin & $0-0.076$ & $71,600-53,600$ \\
\hline Probability of nonattendance-DP & $0-0.448$ & $\begin{array}{c}\text { Dominant* if } \\
\text { probability is }<0.23 \\
33,000-89,400 \\
\text { if probability is }>0.23\end{array}$ \\
\hline Probability of prescription redemption-DP & $0.172-0.308$ & $142,000-33,000$ \\
\hline Utility of a day of treatment failure & $0.646-0.794$ & $40,500-98,600$ \\
\hline \multicolumn{3}{|c|}{$\begin{array}{l}\text { ICUR = incremental cost utility ratio (cost-effectiveness ratio in dollars per quality-adjusted life-year); } \\
\mathrm{GI}=\text { gastrointestinal; } \mathrm{DP}=\text { delayed prescription. }\end{array}$} \\
\hline \multicolumn{3}{|c|}{ * Dominant: option was more effective and less costly than comparative option. } \\
\hline
\end{tabular}

$39 \%$ chance of having an ICUR of less than $\$ 50,000$ per QALY gained and a $61 \%$ chance of having an ICUR of greater than $\$ 50,000$ per QALY gained compared with delayed prescription. Watchful waiting had a $23 \%$ chance of having an ICUR of less than $\$ 50,000$ per QALY gained, a 59\% chance of having an ICUR of greater than $\$ 50,000$ per QALY gained, and a $17 \%$ of being inferior when compared with delayed prescription. Five days of amoxicillin had a 17\% chance of having an ICUR of less than $\$ 50,000$ per QALY gained and an $80 \%$ chance of having an ICUR of greater than $\$ 50,000$ per QALY gained compared with delayed prescription.

\section{DISCUSSION}

\section{Major Findings}

This analysis found that treatment of AOM is a tradeoff between 7 to 10 days of amoxicillin, the most effective strategy, and delayed prescription, the least costly strategy. Children with AOM routinely given amoxicillin for 7 to 10 days gained about 3.5 hours of qualityadjusted life at an additional cost of $\$ 22.90$ compared with children managed with delayed prescription, for an incremental cost of about $\$ 56,000$ per QALY gained. The reduced cost of delayed prescription was achieved through fewer office consultations and less use of antibiotics. In delayed prescription, $37 \%$ of children were not brought in for consultation because parents had learned from prior experience that medical treatment was often not necessary for AOM. Also, children with clinical failure in the delayed prescrip- tion strategy were able to collect their prescription without a second consultation. The increased effectiveness of 7 to 10 days of amoxicillin was achieved by a reduction in the rate of clinical failure. One of the factors that lend credibility to the analysis is the rate of antibiotic administration in the delayed prescription option. The overall rate of $17.9 \%$ is consistent with the $19 \%$ rate of clinical failure found in the placebo groups of meta-analyses, ${ }^{10}$ suggesting that the model appropriately accounted for about the right proportion of children with continued symptoms.

Rather than enabling an absolute statement about which strategy is best for treating AOM, this study's value may be in highlighting the quantifiable costs and benefits that must be accounted for when deciding about treatment of AOM. The effectiveness of antibiotics in reducing the symptoms of AOM by several hours comes at considerable financial cost. Spending an additional $\$ 22.90$ for each of the 13.6 million annual cases of AOM in the United States ${ }^{1}$ treated with 7 to 10 days of amoxicillin instead of delayed prescription would result in an increase of $\$ 311$ million in annual health care expenditures. Because it is not possible to quantify other important benefits of reduced antibiotic use, the results of this analysis surely underestimate the overall economic impact that adoption of delayed prescription could achieve. For instance, the analysis did not include the cost implications of antibiotic resistance or the impact of decreased medicalization of other acute, self-limiting infections, such as lower respiratory tract infections and sore throat. ${ }^{51,52}$

\section{Comparisons With Other Studies}

A review of the literature since 1965 shows there have been 14 economic evaluations of the management of otitis media. ${ }^{2,38-40,53-61}$ Four studies were not specifically restricted to acute disease or were done in settings that could not be compared. ${ }^{88,39,53,54}$ Six studies did not actually perform a cost-effectiveness analysis, but compiled the direct and indirect costs or national estimates of the cost and disease burden of AOM. ${ }^{2,48,55-58}$ Thus, only 4 cost-effectiveness evaluations of AOM have been done in the United States. ${ }^{40,59-61}$ These 4 studies varied widely in approach. In general, none of them were performed based on the recommendations of the US Public 
Health Service panel on Cost-effectiveness Analysis. ${ }^{62}$ More importantly, none included the management options of watchful waiting or delayed prescription.

\section{Limitations}

The analysis has several limitations worthy of discussion. The assumption with the largest impact on the results is the rate of nonattendance in the delayed prescription strategy. The baseline rate of $37 \%$ was chosen from the only trial that evaluated delayed prescription using the approach of having the patient return to collect the prescription rather than of distributing it at the time of consultation. ${ }^{21}$ The rate was obtained from a posttrial survey in which only $63 \%$ of parents in the delayed prescription treatment arm stated that they were very likely to consult a physician in the future for an episode of AOM. And other studies, although not inquiring directly about the likelihood of future consultation, have demonstrated very high levels of parental satisfaction with a similar approach, suggesting that the rate of nonattendance could exceed $37 \%$ as parents become accustomed to the safety of waiting for a few days to see if symptoms improve. ${ }^{22}$

Another area of concern is the assignment of utility values to young children, as they cannot be directly queried regarding their preference for various health states through a standard gamble assessment. The utility values used in this analysis were derived from a postal survey of an expert panel.$^{40}$ Although the actual values cannot be verified, the utility scores allow for a comparison of effectiveness between treatment approaches. All the children in the observational and routine amoxicillin approaches with spontaneous resolution or clinical failure were assigned the same utility scores with an allowance for antibiotic adverse effects when antibiotics were prescribed.

As mentioned previously, the costs and benefits of increasing antibiotic use cannot be quantified, however, the impact is real. For instance, in Iceland, when a national campaign to decrease antibiotic treatment for otitis media was instituted, the rate of carriage of penicillin-resistant pneumococci decreased within 3 years. ${ }^{18}$ It has furthermore been demonstrated that among children with AOM, Streptococcus pneumoniae isolates obtained 10 days after presentation are less likely to be resistant in children managed with observation than in children routinely treated with antibiotics. ${ }^{23}$ Greater use of delayed prescription, through decreased antibiotic use, would likely have an impact on antibiotic resistance because of the large number of children with AOM.

Based on the assumptions in this analysis, children with AOM would receive the most benefit, although at considerable cost, through a strategy of routine amoxicillin treatment for 7 to 10 days. Delayed prescription, the least costly option, would not only save the health service industry considerable expense but would also promote demedicalization of a common, primarily selflimiting acute upper respiratory infection and lessen antibiotic resistance. Lastly, the results of this analysis support the recent guideline of the American Academy of Pediatrics and the American Academy of Family Physicians that includes an observational option for lower-risk children with AOM. ${ }^{25}$

To read or post commentaries in response to this article, see it online at http://www.annfammed.org/cgi/content/full/5/1/29.

Key words: Acute otitis media; cost-effectiveness analysis; decision analysis; health care use; disease management; children; antibiotics; watchful waiting

Submitted January 30, 2006; submitted, revised, May 3, 2006; accepted May 22, 2006.

A version of this report was presented at the Pennsylvania Academy of Family Medicine Research Day, April 2003, Philadelphia, Pa.

Funding support: The Lancaster General Hospital and the American Academy of Family Practice Grant generating project provided support in completing this research.

\section{References}

1. Centers for Disease Control and Prevention. NAMCS, National Ambulatory Medical Care Survey. Available at: http://www.cdc. gov/nchs/about/major/ahcd/surinst.htm\#Survey $\% 20$ Instrument $\% 20$ NAMCS.

2. Takata G, Chan L, Ernst R, Shekelle P, Marcy S. Management of Acute Otitis Media. Evidence Report/Technology Assessment No. 15. Rockville, MD: Agency for Health Care Policy and Research, Public Health Service, US Department of Health and Human Services; AHRQ Publication No. 01-E010.

3. McCaig LF, Hughes JM. Trends in antimicrobial drug prescribing among office-based physicians in the United States. JAMA. 1995;273(3):214-219.

4. Paradise JL, Rockette HE, Colborn DK, et al. Otitis media in 2253 Pittsburgh-area infants: prevalence and risk factors during the first two years of life. Pediatrics. 1997;99(3):318-333.

5. Froom J, Culpepper L, Jacobs M, et al. Antimicrobials for acute otitis media? A review from the International Primary Care Network. BMJ. 1997;315(7100):98-102.

6. Culpepper L, Froom J. Routine antimicrobial treatment of acute otitis media: is it necessary? JAMA. 1997;278(20):1643-1645.

7. McConaghy JR, Smith SR. Controversy in otitis media management: should we follow the CDC recommendations? Am Fam Physician. 2000;61(2):317-318.

8. Del Mar C, Glasziou P, Hayem M. Are antibiotics indicated as initial treatment for children with acute otitis media? A meta-analysis. BMJ. 1997;314(7093):1526-1529.

9. Glasziou PP, Hayem M, Del Mar CB. Antibiotics for acute otitis media in children. Cochrane Database Syst Rev. 2000;(2):CD000219.

10. Takata GS, Chan LS, Shekelle P, et al. Evidence assessment of management of acute otitis media: I. The role of antibiotics in treatment of uncomplicated acute otitis media. Pediatrics. 2001;108(2): 239-247. 
11. Rosenfeld RM, Vertrees JE, Carr J, et al. Clinical efficacy of antimicrobial drugs for acute otitis media: metaanalysis of 5400 children from thirty-three randomized trials. J Pediatr. 1994;124(3):355-367.

12. Chan LS, Takata GS, Shekelle P, et al. Evidence assessment of management of acute otitis media: II. Research gaps and priorities for future research. Pediatrics. 2001;108(2):248-254.

13. van Buchem FL, Peeters MF, van 't Hof MA. Acute otitis media: a new treatment strategy. Br Med J (Clin Res Ed). 1985;290(6474):1033-1037.

14. Dowell SF, Schwartz B. Resistant pneumococci: protecting patients through judicious use of antibiotics. Am Fam Physician. 1997;55(5): 1647-1654, 1657-1658.

15. Block SL, Harrison CJ, Hedrick JA, et al. Penicillin-resistant Streptococcus pneumoniae in acute otitis media: risk factors, susceptibility patterns and antimicrobial management. Pediatr Infect Dis J. 1995;14(9):751-759.

16. Reichler MR, Allphin AA, Breiman RF, et al. The spread of multiply resistant Streptococcus pneumoniae at a day care center in Ohio. J Infect Dis. 1992;166(6):1346-1353.

17. Arason VA, Kristinsson KG, Sigurdsson JA, et al. Do antimicrobials increase the carriage rate of penicillin resistant pneumococci in children? Cross sectional prevalence study. BMJ. 1996;313(7054): 387-391.

18. Stephenson J. Icelandic researchers are showing the way to bring down rates of antibiotic-resistant bacteria. JAMA. 1996;275(3):175.

19. Whitney CG, Farley MM, Hadler J, et al. Increasing prevalence of multidrug-resistant Streptococcus pneumoniae in the United States. N Engl J Med. 2000;343(26):1917-1924.

20. Schwartz B, Bell DM, Hughes JM. Preventing the emergence of antimicrobial resistance. A call for action by clinicians, public health officials, and patients. JAMA. 1997;278(11):944-945.

21. Little P, Gould C, Williamson I, et al. Pragmatic randomised controlled trial of two prescribing strategies for childhood acute otitis media. BMJ. 2001;322(7282):336-342.

22. Siegel RM, Kiely M, Bien JP, et al. Treatment of otitis media with observation and a safety-net antibiotic prescription. Pediatrics. 2003;112(3 Pt 1):527-531.

23. McCormick DP, Chonmaitree T, Pittman C, et al. Nonsevere acute otitis media: a clinical trial comparing outcomes of watchful waiting versus immediate antibiotic treatment. Pediatrics. 2005;115(6): 1455-1465.

24. Marchetti F, Ronfani L, Nibali SC, Tamburlini G. Delayed prescription may reduce the use of antibiotics for acute otitis media: a pro spective observational study in primary care. Arch Pediatr Adolesc Med. 2005;159(7):679-684.

25. American Academy of Pediatrics Subcommittee on Management of Acute Otitis Media. Diagnosis and management of acute otitis media. Pediatrics. 2004;113(5):1451-1465

26. Appelman C, Bossen P, Dunk J, et al. Nederlands Huisarts en Genootschap standaard Otitis Media Acuta. Huisarts Wet. 1990;33:242-245

27. Froom J, Culpepper L, Green LA, et al. A cross-national study of acute otitis media: risk factors, severity, and treatment at initial visit. Report from the International Primary Care Network (IPCN) and the Ambulatory Sentinel Practice Network (ASPN). J Am Board Fam Pract. 2001;14(6):406-417.

28. Kaleida $\mathrm{PH}$, Casselbrant $\mathrm{ML}$, Rockette $\mathrm{HE}$, et al. Amoxicillin or myringotomy or both for acute otitis media: results of a randomized clinical trial. Pediatrics. 1991;87(4):466-474.

29. Kozyrskyj AL, Hildes-Ripstein GE, Longstaffe SE, et al. Treatment of acute otitis media with a shortened course of antibiotics: a metaanalysis. JAMA. 1998;279(21):1736-1742

30. Burke P, Bain J, Robinson D, Dunleavey J. Acute red ear in children: controlled trial of non-antibiotic treatment in general practice. $B M J$. 1991;303(6802):558-562.
31. Damoiseaux RA, van Balen FA, Hoes AW, Verheij TJ, de Melker RA. Primary care based randomised, double blind trial of amoxicillin versus placebo for acute otitis media in children aged under 2 years. BMJ. 2000;320(7231):350-354.

32. Ruben R. Sequelae of antibiotic therapy. In: Rosenfeld R, Bluestone C, eds. Evidence-Based Otitis Media. Hamilton, Ontario: BC Decker Inc; 1999:303-314.

33. Van Zuijlen DA, Schilder AG, Van Balen FA, Hoes AW. National differences in incidence of acute mastoiditis: relationship to prescribing patterns of antibiotics for acute otitis media? Pediatr Infect Dis J. 2001;20(2):140-144.

34. Hamill PV, Drizd TA, Johnson CL, et al. Physical growth: National Center for Health Statistics percentiles. Am J Clin Nutr. 1979;32(3): 607-629.

35. Staff ME, ed. Drug Topics: 2001 Red Book. Oradell, NJ: Medical Economics Company; 2002.

36. Pennsylvania Department of Public Welfare. Office of Medical Assistance Programs Web site. Available at: http://www.dpw.state. pa.us/omap/dpwomap.asp. Accessed April 2003.

37. Briggs $\mathrm{AH}$. Handling uncertainty in cost-effectiveness models. Pharmacoeconomics. 2000;17(5):479-500.

38. Callahan CW Jr. Cost effectiveness of antibiotic therapy for otitis media in a military pediatric clinic. Pediatr Infect Dis J. 1988;7(9): $622-625$

39. Amadasun J. The cost-effective medical treatment of suppurative otitis media in a Nigerian environment. W African J Med. 1997; 16:185-187.

40. Oh PI, Maerov P, Pritchard D, et al. A cost-utility analysis of secondline antibiotics in the treatment of acute otitis media in children. Clin Ther. 1996;18(1):160-182

41. Luntz M, Brodsky A, Nusem S, et al. Acute mastoiditis-the antibiotic era: a multicenter study. Int J Pediatr Otorhinolaryngol. 2001;57(1):1-9

42. Harley EH, Sdralis T, Berkowitz RG. Acute mastoiditis in children: a 12-year retrospective study. Otolaryngol Head Neck Surg. 1997; 116(1):26-30

43. Gliklich RE, Eavey RD, lannuzzi RA, Camacho AE. A contemporary analysis of acute mastoiditis. Arch Otolaryngol Head Neck Surg. 1996;122(2):135-139.

44. Hoppe JE, Koster S, Bootz F, Niethammer D. Acute mastoiditisrelevant once again. Infection. 1994;22(3):178-182.

45. Centers for Medicare and Medicaid. National Procedures Summary File. Available at: http;/www.cms.hhs.gov/ICD9ProviderDiagnosticCode. Accessed March 2003.

46. Agency for Healthcare Research and Quality. HCUPnet, Healthcare Cost and Utilization Project. Available at: http://hcupnet.ahrq.gov/.

47. Marx J, Hockberger R, Walls R, eds. Rosen's Emergency Medicine: Concepts and Clinical Practice. 5th ed. Philadelphia, Pa: Elsevier Science; 2002.

48. Capra AM, Lieu TA, Black SB, et al. Costs of otitis media in a managed care population. Pediatr Infect Dis J. 2000;19(4):354-355.

49. Bureau of Labor Statistics. National Compensation Survey. 2001. Available at: http://www.bls.gov/ncs/home.htm. Accessed March 2003.

50. US Department of Labor, Bureau of Labor Statistics. Consumer Price Indexes. Available at: http://www.bls.gov/cpi/. Accessed March 2003.

51. Little P, Gould C, Williamson I, et al. Reattendance and complications in a randomised trial of prescribing strategies for sore throat: the medicalising effect of prescribing antibiotics. BMJ. 1997;315(7104):350-352

52. Little P, Rumsby K, Kelly J, et al. Information leaflet and antibiotic prescribing strategies for acute lower respiratory tract infection: a randomized controlled trial. JAMA. 2005;293(24):3029-3035. 
53. Bisonni RS, Lawler FH, Pierce L. Recurrent otitis media: a cost-utility analysis of simulated treatment using tympanostomy tubes vs antibiotic prophylaxis. Fam Pract Res J. 1991;11(4):371-378.

54. Alsarraf R, Jung CJ, Perkins J, et al. Measuring the indirect and direct costs of acute otitis media. Arch Otolaryngol Head Neck Surg. 1999;125(1):12-18.

55. Berman S, Roark R, Luckey D. Theoretical cost effectiveness of management options for children with persisting middle ear effusions. Pediatrics. 1994;93(3):353-363.

56. Gates GA. Cost-effectiveness considerations in otitis media treatment. Otolaryngol Head Neck Surg. 1996;114(4):525-530.

57. Kaplan B, Wandstrat TL, Cunningham JR. Overall cost in the treatment of otitis media. Pediatr Infect Dis J. 1997;16(2 Suppl):S9-11.

58. Stool SE, Field MJ. The impact of otitis media. Pediatr Infect Dis J. 1989;8(1 Suppl):S11-14
59. Branthaver B, Greiner DL, Eichelberger B. Determination of costeffective treatment of acute otitis media from $\mathrm{HMO}$ records. Am J Health Syst Pharm. 1997;54(23):2736-2740.

60. Landholt TF, Kotschwar TR. A pharmacoeconomic comparison of amoxicillin/clavulanate and cefpodoxime proxetil in the treatment of acute otitis media. Clin Ther. 1994;16(2):327-333; discussion 271-322.

61. Weiss JC, Melman ST. Cost effectiveness in the choice of antibiotics for the initial treatment of otitis media in children: a decision analysis approach. Pediatr Infect Dis J. 1988;7(1):23-26.

62. Gold M, Siegel G, Russell L, Weinstein M, eds. Cost-Effectiveness in Health and Medicine. New York, NY: Oxford University Press; 1996. 